\title{
Mental health literacy among caregivers of persons with mental illness: A descriptive survey
}

\author{
Vijayalakshmi Poreddi, Raju BIrudu', Rohini Thimmaiah², Suresh Bada Math ${ }^{3}$ \\ Department of Nursing, College of Nursing, ${ }^{1}$ Department Psychiatric Social Work, ${ }^{3}$ Psychiatry, National Institute of Mental Health and \\ Neuro Sciences, Institute of National Importance, ${ }^{2}$ Department of Psychiatry, Videhi Medical College, Bangalore, Karnataka, India
}

\begin{abstract}
Background: Despite of growing evidence of mental disorders in developing countries, research on mental health literacy is limited from India. Aim: To examine mental health literacy among caregivers of persons with mental illness Materials and Methods: A cross-sectional descriptive survey was carried out among 161 randomly selected caregivers of persons with mental illness at outpatient department of a tertiary care centre. Data was collected through face to face interview using a structured questionnaire. Results: Regarding the causes of mental illness, a majority agreed that genetic inheritance $(69 \%)$, substance abuse $(64 \%)$ and brain disease $(59.6 \%)$ are main factors for developing mental illness. Although more than two-thirds agreed that anyone could suffer from mental illness, $61.5 \%$ also agreed that people with mental health problems are largely to blame for their condition. The majority of the participants also agreed that mentally ill are not able to maintain friendships (45.9\%), are dangerous (54\%), and not capable to work $(59.1 \%)$. Just over half $(55.9 \%)$ of the participants would not want people to know if they had a mental illness and nearly half of them also expressed that they would feel ashamed if a family member had a mental illness. Conclusion: Based on the findings of the present study researchers suggest that there is an urgent need to educate and change the attitudes of caregivers through mental health literacy programs specifically designed for them.
\end{abstract}

Key words: Attitudes, caregivers, India, mental health literacy

\section{Introduction}

Mental illness is a global public health concern. ${ }^{[1]}$ According World Health Organization estimation, mental disorders constitute $14 \%$ of the global burden of disease ${ }^{[2]}$ and the overall prevalence rate of mental disorders in India is 10-12 percent. ${ }^{[3]}$ In addition, the Global Burden of Disease Study 2010 (GBD 2010) stated that major depressive disorder is one of the top five leading causes of Years lived with disability (YLD) in India. ${ }^{[4]}$ Being a developing country, in India there are paucity of mental health professionals for instance, psychiatrists $<0.5$ per 100,000 population. ${ }^{[5]}$ Majority of the population live in rural areas and it was found that about $80 \%$ to $90 \%$ of

\begin{tabular}{|l|l|}
\hline \multicolumn{2}{|c|}{ Access this article online } \\
\hline Quick Response Code: & Website: \\
\hline & www.ruralneuropractice.com \\
\cline { 2 - 3 } & \\
\hline & \\
&
\end{tabular}

the mental disorders were undiagnosed and untreated ${ }^{[6]}$ due to lack of knowledge and negative attitudes toward mental illness. Further, stigma and negative attitudes toward people with mental illness have been observed to be common worldwide among general population. ${ }^{[7]}$

In Indian culture, family is regarded as the most important structure in caring for vulnerable family members including those with mental illness and more than $90 \%$ of patients with chronic mental illness live with their families. ${ }^{[8]}$ The caregivers not only provide the basic needs of care like long-term assistance of housing and financial aid, ${ }^{[9]}$ they also take care of the day-to-day needs of the people with mental illness, monitoring the mental state, identify the early signs of illness, relapse and deterioration, and help the patient in accessing services. The family caregiver also supervises treatment and provides emotional support to the patient. ${ }^{[10]}$ However, the lack of knowledge and relatively lower mental health literacy pose challenges to family caregivers, mental health patients and service providers. ${ }^{[11]}$ Nevertheless, people's symptom-management activities will be

Address for correspondence:

Mrs. Vijayalakshmi Poreddi, Department of Nursing, College of Nursing, National Institute of Mental Health and Neuro Sciences, Institute of National Importance, Bangalore - 560 029, Karnataka, India. E-mail: pvijayalakshmireddy@gmail.com 
influenced by mental health literacy. Mental health literacy has been defined as knowledge and beliefs about mental disorders, which aid their recognition, management or prevention. ${ }^{[12]}$ Further, researchers have suggested that mental health literacy is not a single dimension but rather represents knowledge and beliefs about mental health disorders that emerge from general pre-existing belief systems. ${ }^{[13]}$ However, most of the literature found that mental health literacy among the public is unfortunately poor. ${ }^{[14]}$

Most of the mental health literacy surveys have been conducted in western countries, ${ }^{[15-17]}$ with few studies in Indian cultural context. ${ }^{[18,19]}$ Furthermore, no published research available specially was focusing on mental health literacy among caregivers of persons with mental illness from India. Therefore, the present study was aimed to examine the mental health literacy among caregivers of persons with mental illness.

\section{Materials and Methods}

\section{Research design}

This study was a descriptive study carried out among caregivers of people with mental illness at Out Patient Department tertiary care centre, Bangalore, South India.

Participants were selected through a random sampling method from the outpatient follow-up cohort. Caregivers of every fifth patient among first hundred according to the outpatient register were invited to participate in the study. The study criteria included: (a) Their relative must be diagnosed as mentally ill as per ICD-10 criteria, (b) aged above 18 years old, (c) must be the main caregiver, (d) more than 6 months caring for mentally ill patients and (e) should be willing to participate in the study. The relatives of patients with substance abuse or mental retardation were excluded. In the concerned hospital, approximately 300 adult patients per day visit the follow-up OPD. Everyday approximately 15 caregivers were eligible to participate in the study. However, few refused to participate in the study due to lack of interest, lack of time and were unable to manage the patients. Overall 230 caregivers were included in the study over a period of 3 weeks and the final sample comprised of 161 caregivers with $70 \%$ response rate.

\section{Study instrument}

The first part of the questionnaire included socio-demographic details of participants such as age, gender, education, income, marital status, religion, residence and relationship with patient.

The second part of the questionnaire collected information regarding mental health literacy of the caregivers by using
"Public Perception of Mental Illness Questionnaire."[20] This instrument had 33 items that measured mental health literacy of the participants regarding etiology of mental illness (6 items), knowledge of people with mental illness ( 6 items) and attitude toward people with mental health problems (12 items), and management of people with mental health problems (9 items). Answers were coded on a 5-point scale (agree, somewhat agree, neutral, somewhat disagree, disagree). The English version of the questionnaire was used to collect the data. There were no studies of its reliability. The scale's reliability assessment was done by using the test-retest method. The researchers administered the tool among a group of caregivers $(n=16)$ at the follow-up outpatient through face to face interview method over a 2 week period and it was found that the study was suitable to Indian context. The reliability coefficient for the structured questionnaire was 0.85 .

Data was collected by the primary author through a face-to-face interview in a private room at the treatment facilities where the participants were recruited. The interview took approximately 25-30 min to complete.

\section{Ethical consideration}

After obtaining formal permission from authorities, researchers explained the aims and methods of the study to all participants. Questions regarding the study were invited from the participants and they were given freedom to leave the study whenever they desire and also they were assured that withdrawal from this study will not affect the treatment of their relative.

\section{Data analysis}

Descriptive statistics were used and results were narrated in the form of tables.

\section{Results}

The present study investigated mental health literacy among 161 caregivers of the persons with mental illness, of whom $59 \%(n=95)$ of them were women. The majority of the participants $(n=92,57.2 \%)$ were aged between 36 and 55 years. The majority of the participants were married $(n=139,86.3 \%)$ and Hindus ( $n=135,83.9 \%)$. Nearly half $(n=68,42.3 \%)$ of the participants were illiterates/primary education and $60.2 \%$ of them were from the rural background. Almost all participants $(95.7 \% ; n=154)$ of the caregivers were family members [Table 1].

Table 2 shows the responses of the participants to various dimensions of the public perceptions of mental illness questionnaire. Concerning the etiology 
Table 1: Socio-demographic characteristics of participants

\begin{tabular}{|c|c|c|c|}
\hline Variables & Groups & Frequency & Percentage \\
\hline \multirow[t]{5}{*}{ Age } & $<25$ & 22 & 13.7 \\
\hline & $26-35$ & 31 & 19.3 \\
\hline & $36-45$ & 56 & 34.8 \\
\hline & $46-55$ & 36 & 22.4 \\
\hline & $>55$ & 16 & 9.9 \\
\hline \multirow[t]{2}{*}{ Gender } & Male & 66 & 41 \\
\hline & Female & 95 & 59 \\
\hline \multirow[t]{3}{*}{ Religion } & Hindu & 135 & 83.9 \\
\hline & Muslim & 15 & 9.3 \\
\hline & Christian & 11 & 6.8 \\
\hline \multirow[t]{2}{*}{ Income } & $<1700$ Rs/- & 52 & 32.3 \\
\hline & >1700 Rs/- & 109 & 67.7 \\
\hline \multirow[t]{3}{*}{ Marital status } & Married & 139 & 86.3 \\
\hline & Unmarried & 17 & 10.6 \\
\hline & Widowed/separated & 5 & 3.1 \\
\hline \multirow[t]{3}{*}{ Education } & Illiterate/primary education & 68 & 42.3 \\
\hline & Secondary education & 88 & 54.6 \\
\hline & Graduation and above & 5 & 3.1 \\
\hline \multirow[t]{3}{*}{ Residence } & Rural & 97 & 60.2 \\
\hline & Semi urban & 48 & 29.8 \\
\hline & Urban & 16 & 9.9 \\
\hline \multirow{2}{*}{$\begin{array}{l}\text { Relationship } \\
\text { with the patient }\end{array}$} & Family members & 154 & 95.7 \\
\hline & Relatives/friends & 7 & 4.3 \\
\hline
\end{tabular}

of mental illness, $69 \%$ of the participants agreed that mental illness caused by genetic inheritance followed by substance abuse (64\%). However, $45.9 \%$ felt that mental illness because of personal weakness. Regarding knowledge of people with mental illness, a majority of the participants $(68.4 \%)$ agreed that anyone could suffer from mental illness. However, $61.5 \%$ of them agreed that people with mental health problems are largely to blame for their condition and are usually dangerous $(n=87$, $54 \%)$. The participants toward people with mental illness expressed mixed opinions. While $47.8 \%$ of them agreed that people with mental illness could get married, $54.7 \%$ of them disapproved to marry a person with mental illness. Nearly two-thirds (62.2\%) approved that people with mental illness have the same rights as anyone else. However, 55.9\% would not want people to know if they had a mental illness and feel ashamed if a family member had a mental illness. Concerning care and management of the people with mental illness, nearly half thought they could hide his/her mental illness from his/her family and believed that mental illness neither can be cured nor recover from mental illness. Nearly two thirds of them approved that people with mental illness should be in an institution under supervision and control. Nonetheless, $44.1 \%$ of the participants disapproved that Primary Health care Centers (PHC) provides good care for mental illnesses.

\section{Discussion}

This present study was aimed to examine mental health literacy among caregivers of people with mental illness. The few studies that were conducted in India so far either mainly focused on relationship between first treatment contact and supernatural beliefs in caregivers of patients with schizophrenia ${ }^{[18,21-23]}$ or religious and traditional modes of intervention which are still widely practiced, especially in rural areas, where mental health services are almost nonexistent. ${ }^{[24-26]}$ Yet, we know very little about the caregivers attitude and knowledge toward mental illness. Thus, the present study attempted to investigate the caregivers mental health literacy factors such as etiology, knowledge, attitude and management of people with mental health problems.

In line with findings of the studies, ${ }^{[20,27,28]}$ the caregivers in the present study demonstrated understanding about the reasons for mental illness as majority of them cited mental illness is caused mainly by genetic inheritance, substance abuse, brain disease. However, they also viewed bad things happening, personal weakness and gods' punishment as important factors. Similar to these findings, Kermode et al. (2009) found that the most commonly acknowledged causes for mental illness were a range of socio-economic factors (conflict with family, at work and with neighbors; an addicted family member; not being married; crisis; bereavement; problems from childhood; financial difficulties; poverty), while neither supernatural causes nor biological explanation were widely endorsed. ${ }^{[18]}$ On the other hand, a number of studies from India demonstrated peoples' belief in supernatural powers as the causative agents of mental illness. ${ }^{[29-32]}$ However, it can be argued that similar to other studies the participants in the present study were caregivers and they learnt about mental illness through their experiences of caring for a person with mental illness. ${ }^{[11,33]}$

The majority of caregivers in the present study accepted that anyone can experience mental health problem reflecting the findings of the previous studies. ${ }^{[20,34]}$ Like previous research, the participants hold negative perceptions such as mentally ill are to blame for their condition, not capable to work or to maintain friendships. ${ }^{[34]}$ Similarly, the participants had negative attitudes toward mentally ill. However, nearly two thirds of the participants agreed that people with mental illness should have the same rights as anyone else. In a recent survey, $36.9 \%$ of rural subjects, $43.2 \%$ of urban subjects, and $44.7 \%$ of the medical professionals reported that they would oppose marriage with a person recovered from 
Table 2: Responses of the participants to the public perception of mental illness questionnaire

\begin{tabular}{|c|c|c|c|}
\hline \multirow[t]{2}{*}{ Statements } & \multicolumn{3}{|c|}{$N(\%)$} \\
\hline & $\begin{array}{c}\text { Agree/ } \\
\text { strongly agree }\end{array}$ & Neutral & $\begin{array}{c}\text { Disagree } \\
\text { strongly/disagree } \\
\end{array}$ \\
\hline \multicolumn{4}{|l|}{ Cause of mental illness } \\
\hline Mental illness is caused by genetic inheritance & $111(69)$ & $7(4.3)$ & $43(26.7)$ \\
\hline Mental illness is caused by substance abuse & $103(64)$ & $15(9.3)$ & $43(26.7)$ \\
\hline Mental illness is caused by bad things happening to you & $84(52.2)$ & $19(11.8)$ & $58(36)$ \\
\hline Mental illness is god's punishment & $56(34.8)$ & $21(13)$ & $84(52.1)$ \\
\hline Mental illness is caused by brain disease & $96(59.6)$ & $15(9.3)$ & $50(31)$ \\
\hline Mental illness is caused by a personal weakness & $74(45.9)$ & $36(22.4)$ & $51(31.7)$ \\
\hline \multicolumn{4}{|l|}{ Knowledge of people with mental illness } \\
\hline People with mental health problems are largely to blame for their own condition & $99(61.5)$ & $14(8.7)$ & $48(29.8)$ \\
\hline One can always tell a mentally ill person by his or her physical appearance & $91(56.5)$ & $15(9.3)$ & $55(34.1)$ \\
\hline Mentally ill persons are not capable of true friendships & $74(45.9)$ & $21(13)$ & $66(41)$ \\
\hline Mentally ill persons can work & $95(59.1)$ & $23(14.3)$ & $43(21.1)$ \\
\hline Mentally ill persons are usually dangerous & $87(54)$ & $24(14.9)$ & $50(31)$ \\
\hline Anyone can suffer from a mental illness & $110(68.4)$ & $9(5.6)$ & $42(26.1)$ \\
\hline \multicolumn{4}{|l|}{ Attitude toward people with mental illness } \\
\hline The mentally ill should be prevented from having children & $79(49)$ & $12(7.5)$ & $70(43.4)$ \\
\hline The mentally ill should not get married & $70(43.5)$ & $14(8.7)$ & $77(47.8)$ \\
\hline One should avoid all contact with the mentally ill & $55(34.2)$ & $19(11.8)$ & $87(44)$ \\
\hline $\begin{array}{l}\text { The mentally ill should not be allowed to make decisions, even those concerning routine } \\
\text { events }\end{array}$ & $75(46.6)$ & $9(5.6)$ & $77(47.9)$ \\
\hline I could maintain a friendship with someone with a mental illness & $80(49.7)$ & $9(5.6)$ & $72(44.7)$ \\
\hline I could marry someone with a mental illness & $53(32.9)$ & $20(12.4)$ & $88(54.7)$ \\
\hline I would be afraid to have a conversation with a mentally ill person & $62(38.5)$ & $28(17.4)$ & $71(44.1)$ \\
\hline People with mental health illnesses should have the same rights as anyone else & $100(62.2)$ & $17(10.6)$ & $44(27.3)$ \\
\hline I would be upset or disturbed about working on the same job as a mentally ill peers & $64(39.8)$ & $18(11.2)$ & $89(49.1)$ \\
\hline $\begin{array}{l}\text { I would be ashamed if people knew that someone in my family had been diagnosed with a } \\
\text { mental illness }\end{array}$ & $77(47.8)$ & $18(11.2)$ & $66(41)$ \\
\hline If I was suffering from a mental health illness, I wouldn't want people to know about it & $90(55.9)$ & $16(9.9)$ & $55(34.1)$ \\
\hline People are generally caring and sympathetic toward people with mental illness & $73(45.4)$ & $19(11.8)$ & $69(42.9)$ \\
\hline \multicolumn{4}{|l|}{ Care and management of people with mental illness } \\
\hline One should hide his/her mental illness from his/her family & $76(47.2)$ & $5(3.1)$ & $80(49.6)$ \\
\hline There are mental health services available in my community & $78(48.5)$ & $12(7.5)$ & $71(44.1)$ \\
\hline Mental illness cannot be cured & $72(44.7)$ & $24(14.9)$ & $65(40.4)$ \\
\hline Mentally ill people should be in an institution where they are under supervision and control & $105(65.2)$ & $16(9.9)$ & $40(24.9$ \\
\hline Mental illness can be treated outside a hospital & $77(47.8)$ & $19(11.8)$ & $65(40.3)$ \\
\hline Information about mental illness is available at my $\mathrm{PHC}$ & $67(41.6)$ & $27(16.8)$ & $67(41.6)$ \\
\hline The majority of people with mental illnesses recover & $75(46.6)$ & $31(19.3)$ & $55(34.1)$ \\
\hline Primary health care clinics can provide good care for mental illnesses & $67(41.6)$ & $23(14.3)$ & $71(44.1)$ \\
\hline $\begin{array}{l}\text { If I was concerned about a mental health issue with a member of my family or myself, I } \\
\text { would feel comfortable discussing it with someone at my PHC }\end{array}$ & $80(49.7)$ & $19(11.8)$ & $62(38.5)$ \\
\hline
\end{tabular}

mental illness. ${ }^{[32]}$ Our present study concurs with these findings. However, in both low-income and high-income countries, the stigmatization of people with mental disorders has persisted throughout history. Stigma is manifested as bias, stereotyping, fear, embarrassment, anger, rejection, or avoidance. For people suffering from mental disorders, there have been violations of basic human rights and freedoms, as well as denials of civil, political, economic, and social rights, in both institutions and communities. In a recent descriptive study carried out among recovered mentally ill demonstrated that irrespective of gender, ${ }^{[35]}$ literacy, ${ }^{[36]}$ socioeconomic status $^{[37]}$ and residence, ${ }^{[38]}$ human rights violations are occurring at family and community level. The current study also reveals negative attitudes of participants regarding social participation of mentally ill in the community as they cited they would be ashamed if people knew that someone in their family had been diagnosed with a mental illness as well they would not want people to know about their illness. It clearly shows that stigma and discrimination toward people with mental illness exists. In India, it was found that the main predictor of a variable of social distance from people with mental illness perceived the person as 
dangerous. ${ }^{[18]}$ The present study findings concur with this study as majority (54\%) perceived mentally ill as dangerous. On the other hand, it was generally argued that people do not sympathize with a mentally ill person because they impart value to the patient and believe that the person lacks the will power to pull him or herself up and is just not making an effort. ${ }^{[39]}$ However, nearly half of the participants in the present study agreed that people are generally caring and sympathetic toward people with mental illness. In general, the public tends to view the mentally ill as dangerous, unpredictable and prone to violence. In addition, a recent body of research evidence suggests that patients who suffer from serious mental conditions are more prone to violent behavior than persons who are not mentally ill. ${ }^{[40]}$ Likewise, in the present study also nearly two thirds of participants opined that mentally ill people should be in an institution where they are under supervision and control. These findings were similar to previous studies. ${ }^{[22,23,41]}$ Like other studies, in current study, nearly half of them agreed that they are free to discuss mental health issues related to them or their family members. ${ }^{[20,32]}$ In contrast, most of the studies found that in general people were reluctant to discuss mental disorders with relatives and friends than physical disorders. ${ }^{[42,43]}$ In India, due to stigmatizing attitudes patients have been found to present their distress in somatic rather than psychological terms. ${ }^{[4]}$

\section{Limitations}

The present study has certain limitations such as small sample that was restricted to one tertiary care centre and lack of compare group. Further, the research tool was not validated and there may be the possibility of bias due to social desirability (especially due to the face-to-face interview). Hence, the findings of the study may not be generalized and future research should focus on larger sample and comparative studies with qualitative methods (focus group discussions) may be helpful to understand in depth about this issue. Despite of these limitations, random sample of the present study represent the target population.

\section{Conclusion}

In summary, the present study highlighted that participants had understanding about the causes of mental illness. However, the majority of the participants are holding stigmatizing attitudes toward people with mental illness in relation to social participation, treatment, work, marriage and recovery. Thus, there is an urgent need to educate and change the attitudes of the caregivers regarding mental illness through mental health literacy programs specifically on certain groups within the population who have a particular need for mental health education. Further, mental health professionals should take responsible role in educating these specific populations.

\section{Acknowledgements}

Researchers thank all the participants for their valuable contribution.

\section{References}

1. Lakhan R, Ekúndayò OT. National sample survey organization survey report: An estimation of prevalence of mental illness and its association with age in India. J Neurosci Rural Pract 2015;6:51-4.

2. WHO. WHO Mental Health Gap Action Programme (mhGAP). Available from: http://www.who.int/mental_health/mhgap/en/. [Last accessed on 2014 Oct 25].

3. The Healthsite. Mental Illness Neglected in India. Available from: http://www.thehealthsite.com/diseases-conditions/ mental-illness-neglected-in-india/. [Last accessed on 2014 Nov 26].

4. Global Burden of Diseases (GBD). Global Burden of Diseases: Injuries, and Risk Factors Study. Available from: http://www.healthdata.org/ sites/default/files/files/country_profiles/GBD/ihme_gbd_country_ report_india.pdf. [Last accessed on 2014 Nov 26].

5. Saxena S. Human resources. Workforce. In: Mental Health Atlas. Geneva: WHO; 2011. p. 56-7.

6. Gupta D. Mind snare. Tehalka Magazine [Internet]. May 15. Available from: http://www.tehelka.com/story_main44 asp?filename $=\mathrm{Ne} 150510$ coverstory.asp. Accessed on 2014 Nov 26.

7. Högberg T, Magnusson A, Lützén K, Ewalds-Kvist B. Swedish attitudes towards persons with mental illness. Nord J Psychiatry 2012;66:86-96.

8. Chadda RK. Psychiatric patient in the community: Challenges and solutions. J Ment Health Behav 2001;6:7-15.

9. Hsiao CY, Van Riper M. Research on caregiving in Chinese families living with mental illness: A critical review. J Fam Nurs 2010;16:68-100.

10. Chadda RK. Caring for the family caregivers of persons with mental illness. Indian J Psychiatry 2014;56:221-7.

11. Mohamad MS, Zabidah P, Fauziah I, Sarnon N. Mental health literacy among family caregivers of schizophrenia patients. Asian Soc Sci 2012;8:74-82.

12. Jorm AF, Korten AE, Jacomb PA, Christensen H, Rodgers B, Pollitt P. "Mental health literacy": A survey of the public's ability to recognise mental disorders and their beliefs about the effectiveness of treatment. Med J Aust 1997;166:182-6.

13. Griffiths KM, Christensen H, Jorm AF. Mental health literacy as a function of remoteness of residence: An Australian national study. BMC Public Health 2009;9:92.

14. Furnham A, Abajian N, McClelland A. Psychiatric literacy and personality disorders. Psychiatry Res 2011;189:110-4.

15. Loureiro LM, Jorm AF, Mendes AC, Santos JC, Ferreira RO, Pedreiro AT. Mental health literacy about depression: A survey of portuguese youth. BMC Psychiatry 2013;13:129.

16. Atilola O. Level of community mental health literacy in sub-Saharan Africa: Current studies are limited in number, scope, spread, and cognizance of cultural nuances. Nord J Psychiatry 2014;1-9.

17. Tam LT. Mental health literacy and mental health status in adolescents: A population-based survey. Child Adolesc Psychiatry Ment Health 2014;8:26

18. Kermode M, Bowen K, Arole S, Pathare S, Jorm AF. Attitudes to people with mental disorders: A mental health literacy survey in a rural area of Maharashtra, India. Soc Psychiatry Psychiatr Epidemiol 2009;44:1087-96.

19. Kumar R. Attitude to people with mental illness: A mental health literacy survey from Punjab State. Int J Health Sci Res 2013;3:135-45. 
20. Sadik S, Bradley M, Al-Hasoon S, Jenkins R. Public perception of mental health in Iraq. Int J Ment Health Syst 2010;4:26.

21. Chatterjee S, Chatterjee A, Jain S. Developing community-based services for serious mental illness in a rural setting. In: Patel V, Thara R, editors. Meeting the Mental Health Needs of Developing Countries: NGO Innovations in India. New Delhi: Sage Publications India Pvt Ltd; 2003. p. $115-40$.

22. Kumar D, Kumar P, Singh AR, Bhandari SS. Knowledge and attitude towards mental illness of key informants and general population: A comparative study. Dysphrenia 2012;3:57-64.

23. Poreddi V, Ramachandra, Nagarajaiah, Konduru R, Math SB. Attitude and response of a rural population regarding person with mental illness. Dysphrenia 2013;4:42-8.

24. Kulhara P, Avasthi A, Sharma A. Magico-religious beliefs in schizophrenia: A study from north India. Psychopathology 2000;33:62-8.

25. Padmavati $\mathrm{R}$, Thara $\mathrm{R}$, Corin $\mathrm{E}$. A qualitative study of religious practices by chronic mentally ill and their caregivers in south India. Int J Soc Psychiatry 2005;51:139-49.

26. Patel V, Simunyu E, Gwanzura F. The pathways to primary mental health care in high-density suburbs in Harare, Zimbabwe. Soc Psychiatry Psychiatr Epidemiol 1997;32:97-103.

27. Gureje O, Lasebikan VO, Ephraim-Oluwanuga O, Olley BO, Kola L. Community study of knowledge of and attitude to mental illness in Nigeria. Br J Psychiatry 2005;186:436-41.

28. Ediriweeraa HW, Fernando SM, Pai NB. Mental health literacy survey among Sri Lankan carers of patients with schizophrenia and depression. Asian J Psychiatr 2012;5:246-50.

29. Sethi BB, Sachdeva S, Nag D. Socio-cultural factors in practice of psychiatry in India. Am J Psychother 1965;3:445-54.

30. Sethi BB, Trivedi JK, Sitholey P. Traditional healing practices in psychiatry. Indian J Psychiatry 1977;19:9-13.

31. Trivedi JK, Sethi BB. A psychiatric study of traditional healers in Lucknow city. Indian J Psychiatry 1979;21:133-7.

32. Kishore J, Gupta A, Jiloha RC, Bantman P. Myths, beliefs and perceptions about mental disorders and health-seeking behavior in Delhi, India. Indian J Psychiatry 2011;53:324-9.

33. Wolff G, Pathare S, Craig T, Leff J. Community knowledge of mental illness and reaction to mentally ill people. Br J Psychiatry 1996;168:191-8.

34. Brown M, Derek C. Mental Health in Ireland: Awareness and Attitudes. Ireland: Health Service Executive. 2007.Avaialble at http://www. healthpromotion.ie/hp-files/docs/HSP00612.pdf. Accessed on 2014 Nov 26.
35. Vijayalakshmi P, Reddemma K, Math SB. Gender-related differences in the human rights needs of patients with mental illness. J Nurs Res 2012;20:90-8.

36. Vijayalakshmi P, Ramachandra, Reddemma K, Math SB. Perceived human rights violation in persons with mental illness: Role of education. Int J Soc Psychiatry 2013;59:351-64.

37. Vijayalakshmi P, Ramachandra, Reddemma K, Math SB. Impact of socio-economic status in meeting the needs of people with mental illness; human rights perspective. Community Ment Health J 2014;50:245-50.

38. Poreddi V, Ramachandra, Nagarajaiah, Konduru R, Badamath S. Human rights violations among people with mental illness; rural vs. urban comparison. Turk Psikiyatri Derg 2013;24:168-81.

39. WHO, Regional Office for South-East Asia. Mental health and Substance Abuse, Including Alcohol. New Delhi: WHO Regional Office of South-East Asia; 2001. Available at http://repository.searo.who.int/ handle/123456789/5129. Accessed on 2014 Feb 12.

40. Arboleda-Fl'rez J, Heather H, Annette C. Mental Illness and Violence. Available from: https://www.jicef.or.jp/wahec/ful101.htm. [Last accessed on 2013 Jan 28].

41. Barke A, Nyarko S, Klecha D. The stigma of mental illness in Southern Ghana: Attitudes of the urban population and patients' views. Soc Psychiatry Psychiatr Epidemiol 2011;46:1191-202.

42. Hillert A, Sandmann J, Ehmig SC, Weisbecker H, Kepplinger HM, Benkert O.The general public's cognitive and emotional perception of mental illnesses: An alternative to attitude-research. In: Guimón J, Fischer W, Sartorius N, editors. The Image of Madness: The Public Facing Mental Illness and Psychiatric Treatment. Basel: Karger; 1999. p. 56-71.

43. Regier DA, Hirschfeld RM, Goodwin FK, Burke JD Jr, Lazar JB, Judd LL. The NIMH depression awareness, recognition, and treatment program: Structure, aims, and scientific basis. Am J Psychiatry 1988;145:1351-7.

44. Raguram R, Weiss MG, Channabasavanna SM, Devins GM. Stigma, depression, and somatization in South India. Am J Psychiatry 1996;153:1043-9.

How to cite this article: Poreddi V, Blrudu R, Thimmaiah R, Math SB. Mental health literacy among caregivers of persons with mental illness: A descriptive survey. J Neurosci Rural Pract 2015;6:355-60.

Source of Support: Nil. Conflict of Interest: None declared. 